\title{
A Thirty-Port Smoking Machine for Continuous Smoke Generation*
}

\author{
by F. J. Schultz and J. R. Wagner \\ Lorillard Research Center, Greensboro, North Carolina, U.S.A.
}

\section{INTRODUCTION}

During recent years, there has been a steadily growing interest among biomedical research scientists in studying the effects of inhaled cigarette smoke on small animals. One of the serious handicaps faced in these studies has been the lack of availability of apparatus necessary to perform inhalation experiments involving large numbers of animals. A major item required in any such experiment is a madhine capable of producing cigarette smoke in a well defined and consistent manner. In an effort to alleviate this problem, the Council for Tobacco Research U.S.A. (CTR) undertook a program to solicit smoking machine designs from many sources and to evaluate the performance of the madines submitted for testing.

It became apparent during these tests that none of the machines then known to exist would meet the criteria considered necessary for the intended application. Some of the more important criteria were:

1. The machine should smoke cigarettes according to the standard analytical smoking parameters of a puff volume of $35 \mathrm{~cm}^{3}$ taken during a time of 2 seconds duration once each minute.

2. The smoke should be delivered to the test animals with a minimum delay in order to prevent chemical or physical property changes due to aging.

3. A reliable means for providing a known amount of air dilution should be provided.

4. Methods of conveniently monitoring the performance of the madine with respect to the smoking parameters and convenient methods for collecting smoke samples for analysis must be incorporated in the design.

\footnotetext{
- U.S. Pasent No. 3, 732, 874.

Received for publication: 23rd May, 1974.
}

5. The design should provide the capability of exposing large numbers of animals simultaneously.

One direct result of this CTR program was the development of the Walton-Morrissey Smoking Machine $(1,2)$. This machine utilizes the reverse puffing technique and can puff one, two or three cigarettes simultaneously into a chamber which will accommodate the exposure of 12 mice or hamsters at one time.

We were in the process of designing a smoking mahine at the time that the CTR evaluation program was going on. We were therefore in the fortunate position of being able to gain considerable insight into the varjous problems and successes encountered in those tests and to take them into account in the design of our machine. Since there was, and apparently still is, little agreement among researchers on the best way to restrain animals during inhalation experiments, we decided to devote our principal efforts to the design of an apparatus for the production of smoke under closely controlled and well defined conditions, and only secondarily to animal holder systems.

Two general methods of puffing a cigarette are possible. The most common is to draw smoke from the cigarette by application of a vacuum to the butt end. The other, known as reverse smoking, is to force air through the lighted cigarette by applying an elevated pressure to the burning end. The delivery of smoke to animals using the first method would require collecting the smoke drawn from the cigarette and then transferring it to the animal exposure device or placing the animals under reduced pressure during puffing. The disadvantages of this system with respect to the time lapse involved and the handling and transfer of a labile aerosol are obvious. We chose reverse smoking as the preferable method of smoke generation because the smoke could be routed directly to the animal holder from the cigarette butt with a minimum of manipulation and lost time. 
Figure 1. Overall view of the smoking machine.

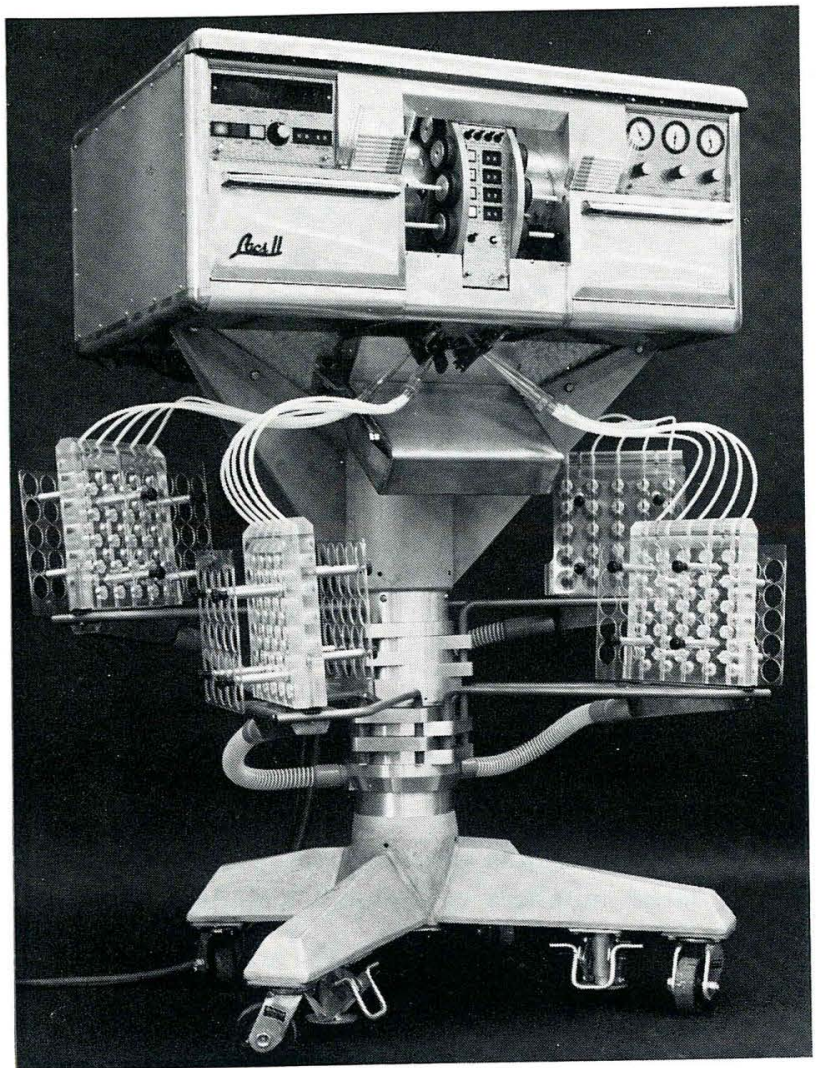

\section{APPARATUS}

Having made this basic commitment to the method of smoking, we designed the apparatus pictured in Figure $I$ and shown diagrammatically in Figure 2 . The operational sequence can best be followed by referring to Figure 2. The puff chamber to the right moves over the cigarette and seals against the cigarette holder. Simultaneously, a calibrated amount of air is admitted to the puff chamber and the central shuttle valve moves to the right to make a seal against the cigarette holder at the butt of the cigarette. The resulting puff profile (Fig. 3), as measured in the puff chamber, is sharply squared on the leading and trailing edges, and is modified during the course of the puff by the burning characteristics of the individual cigarette. During the two-second period while air is being forced through the cigarette and the smoke is being routed out through the shuttle valve channel, the left hand cigarette holder carrousel is being rotated to align the second cigarette with the shuttle valve and the left puff chamber. At the end of a two-second puff of the first cigarette, the left puff chamber moves in and seals over the second cigarette, the shuttle valve moves left and seals over the butt opening, puff air pressure is supplied, and the right puff chamber retracts. During the two-second puff on the second cigarette, the right carrousel moves cigarette number three into position and at the end of the puff on cigarette number two the above cycle is repeated.

Each carrousel holds 15 cigarettes which are puffed
Figure 2. Schematic of smoke generation system.

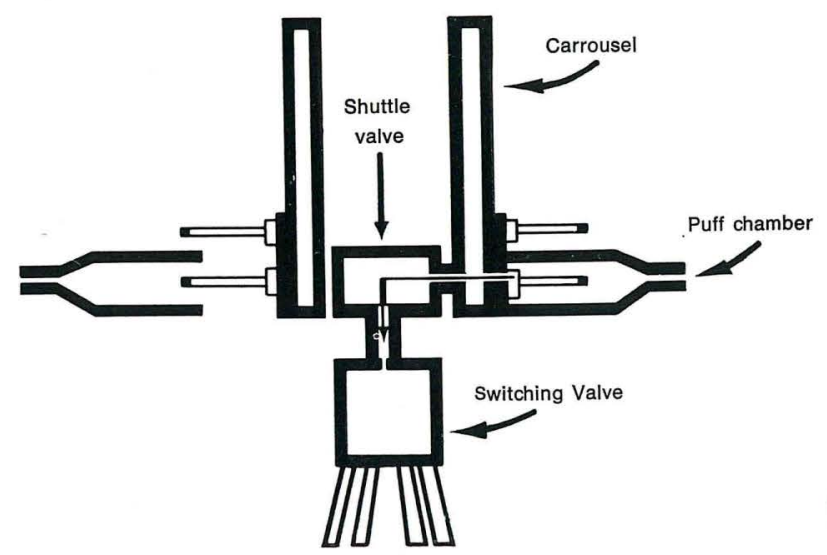

alternately for two seconds each, providing one puff per minute on each cigarette, thus resulting in a constant stream of smoke being emitted from the shuttle valve outlet.

The details of how these functions are made to occur in the proper sequence and at the proper time are beyond the scope of this paper but they are programmed by cam operated switches and air valves in an earlier model and by digital electronics in the model reported here.

The machine is equipped with automatic cigarette loading, lighting, and butt ejecting mechanisms. The automatic lighter (located within the puff chamber) lights each cigarette during the first puff cycle and then turns off until the next group is loaded. The cigarette butts are ejected after a preset number of puffs have been taken on each cigarette.

Since the two-second puff time is preset, the only variables that need to be calibrated to conform to the standard smoking procedures are the puff air volume and the diluting air flow. The $35 \mathrm{ml}$ puff generated is the result of two components; the gases generated by the burning cigarette and the air forced through the cigarette. It is therefore necessary to calibrate this puff on the basis of output smoke rather than input air. This is done by the following procedure.

The machine is loaded with thirty cigarettes and the smoking cycle is begun. The continuous stream of diluted smoke from the machine is delivered into a

Figure 3. Puff profile.

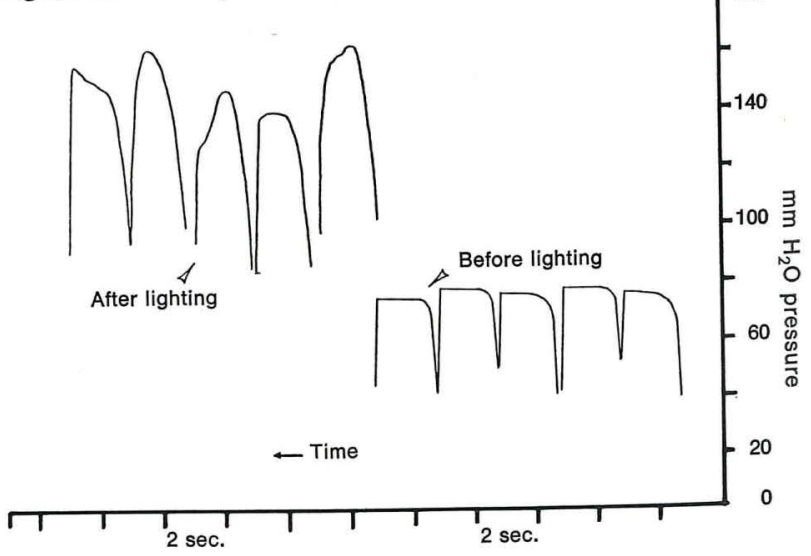


Figure 4. Right hand panel.

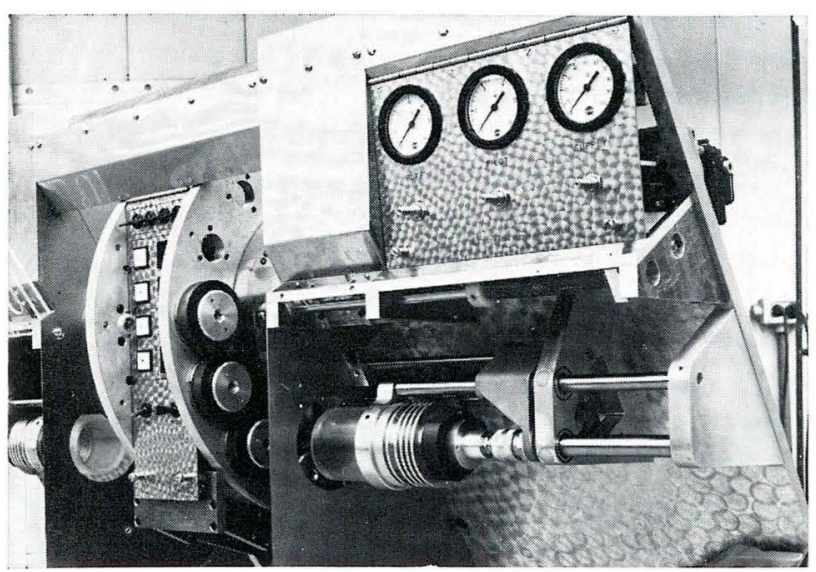

sealed plastic bag contained in a large airtight container. The air displaced from the container may then be measured with a bubble flow meter during each successive puff on the cigarettes. The average of the eight to ten puff volumes may then be calculated. If the puff volume is not $35 \mathrm{~cm}^{3}$ per two-second puff $\pm 0.1\left(1050 \mathrm{~cm}^{3}\right.$ per minute $\left.\pm 3 \mathrm{~cm}^{3}\right)$, the appropriate adjustment is made to the puff air flow control and the above procedure is repeated.

Since the air flow through the cigarette during a puff is a function of the pressure drop across the cigarette, it is necessary to use cigarettes of a relatively uniform pressure drop in order to maintain the calibrated delivery of smoke. It should be noted that the above calibration gives an average $35 \mathrm{ml}$ per puff delivery over the smoking of the whole cigarette to whatever butt length was used in the initial calibration. Each individual puff may not be $35 \mathrm{ml}$ because the early puffs are taken through a higher pressure drop than the later ones and are therefore somewhat smaller in smoke volume delivered.

It is well known that the pressure drop of a cigarette measured before lighting is somewhat less than after it has been lighted and a coal has been established; however, we have found that a relatively firm relationship between the two values does exist. This makes it possible to estimate the puff air pressure which will be required for proper puff volume by knowing the unlighted cigarette pressure drop. This estimate can be used in initially setting up the machine for a particular cigarette sample prior to the actual puff volume calibration. This calibration then needs to be repeated only when a change is made to cigarettes of significantly different pressure drop.

Figure I shows the machine's front panel where the operating controls are located. The air pressure gauges and associated control knobs on the right hand panel (Figure 4 ) are used to obtain the proper puff volume and air dilution ratio.

The four top toggle switches and the four programmable counters in the center panel (Figure 5) control the function of an automatic switching valve located at the exit port of the shuttle valve. This switching valve routes the smoke from the shuttle valve outlet
Figure 5. Center panel.

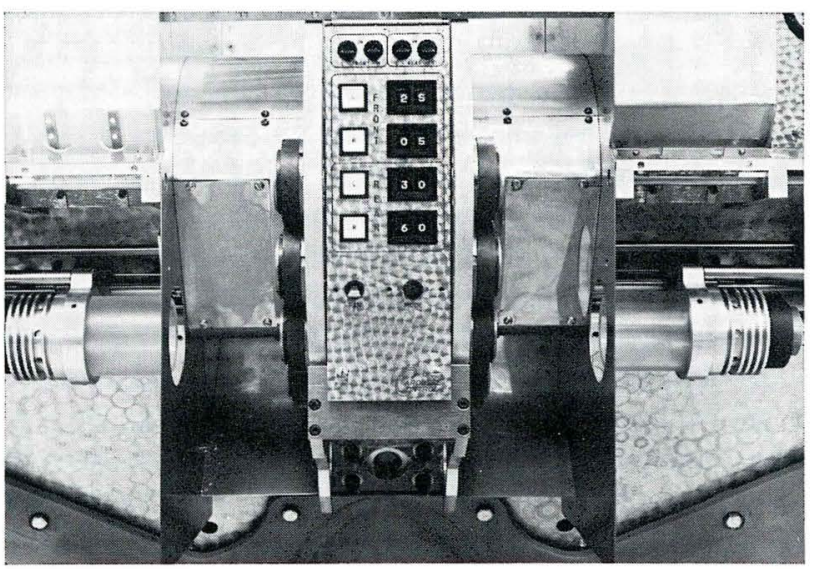

to any or all of the four animal exposure chambers, in sequence, for the number of seconds indicated on the respective counters. The top toggle switches are used to select which exposure chambers should receive smoke. The white toggle switch below the counters can be set in either the A-mode or B-mode position. When in A-mode position, the sum of the times from the activated counters may not be more than 60 seconds. This insures that smoke from each puff of the cigarette will go to each animal holder. That is, each animal holder will get smoke from the first puff of the cigarettes during its first exposure, from the second puff of the cigarettes during its second exposure, etc. If the sum of the times is less than 60 seconds, the smoke generated during the remaining time of each puff cycle will be vented out through the central column and exhausted by a fan incorporated within it. The black toggle switch at the lower left of the center panel operates this exhaust fan.

When the white toggle switch is in the B position, any combination of exposure times up to 99 seconds each may be set into the counters and the respective exposure chambers will receive smoke for the selected number of seconds in turn. It should be noted, however, that if the total of the times selected exceed 60 seconds, not all chambers will receive smoke from the same puff of the cigarette. This may or may not be important depending upon the design of the animal experiment being carried out.

In addition to directing the flow of smoke among the various exposure chambers according to the selected schedule, the switching valve also directs breathing air to the chambers between smoke exposures. This air supply begins immediately when the smoke to a particular chamber is stopped and is supplied at the same flow rate as the smoke had been previously.

Adjustments within the valve itself allow the researcher to select different degrees of smoke dilution for each chamber if he so desires. The available range of smoke concentrations is from $5 \%$ smoke to $20 \%$ smoke and is set by means of individual needle valve adjustments.

The left hand panel contains the controls used to 
start and stop the machine, to determine the number of cigarettes to be loaded, and the number of puffs to be smoked on each cigarette. The lighted display at the top of this panel shows the current status of the machine; that is, the number of cigarettes remaining to be puffed in the current cycle and the number of puffs remaining to be taken on each cigarette. This display also tells which functions are currently being performed by the machine such as loading cigarettes, lighting cigarettes, puffing, or ejecting butts. A warning light, also in this display, will appear if there is a malfunction of the machine.

The push-button switches to the left side of the left hand control panel are the start, stop and reset switches. If it is necessary to stop the machine for any reason while it is in operation, this can be done by simply pressing the stop switch. Two options are then available for restarting the machine. Pressing the start switch will restart the operations from where ever in the sequence they were stopped or if one desires to start over from the beginning, this is accomplished by pressing the reset switch followed by the start switch. The machine will then start in the loading and lighting cycle.

The round selector switch in the center of the left hand panel is the main power switch for the machine and is used to select stand-by, single cycle, or multiple cycle modes or to put the machine in test mode. Moving this selector from off to stand-by supplies power to all of the electrical circuits of the machine but does not start any of the operations. The single cycle mode setting will, after pressing the start switch, allow the machine to operate through one complete cycle of loading, lighting, smoking and ejecting. The machine will then automatically stop. If the multiple cycle mode is selected, the machine will automatically start a second, third, etc. cycle as soon as the previous one has been completed. In this mode, new cigarettes are loaded and lighted as old ones are being ejected so that there is no break in the supply of smoke to the switching valve. The cigarettes are supplied from cartridge type magazines which can be filled off the machine and inserted by the operator during each cycle to provide cigarettes for the next loading.

The two programmable counters at the right of the left hand panel are used to select the number of puffs to be taken on each cigarette during each complete machine cycle and to select the number of cigarettes to be loaded during each cycle. The maximum number of cigarettes which can be loaded for each cycle is, of course, 30 and the maximum number of puffs per cigarette is determined by the burning rate of the particular cigarettes being used in the experiment and the butt length desired. A minimum butt length of about $25 \mathrm{~mm}$ should be observed to prevent possible damage to the cigarette holders and to assure proper operation of the butt ejecting device.

With the mode selector knob in the test position, a series of test circuits are activated which are controlled by individual function switches located on the back of the smoking machine. They are included as an aid to trouble shooting in case of machine malfunction. As stated earlier, the machine is controlled primarily with digital logic circuits. The electrical components responsible for each function are located on printed circuit boards so that should trouble develop with a certain function, that board can be quickly replaced: Each function such as right puff chamber, left puff chamber, right loader, left loader, right ejector, left ejector, etc. has its own switch on the back of the machine so that each can be operated separately in the test mode, thus making it easy to isolate a source of trouble.

A similar arrangement is provided for all pneumatic functions through appropriate test circuits also located on the back panel. The components which control the various pneumatically activated functions are grouped so that the components responsible for each function are included in a plug-in module, analogous to an electronic circuit board, so that it can be quickly removed and replaced if trouble develops within it. Arrangements have been made with an instrument manufacturer (3) to make the machine described here, and a simpler, less sophisticated model available commercially. Any inquiries regarding availability should be directed to this manufacturer.

\section{RESULTS AND DISCUSSION}

In order to establish that the smoke produced by this reverse smoking technique is equivalent to that produced from the same cigarettes by the vacuum puffing method, a number of chemical parameters were measured on the smoke produced by this machine and a standard analytical smoking machine using Kentudky Reference IRI cigarettes.

In order to be sure that the calibration of the puff volume to an average value of $35 \mathrm{ml}$ per puff over eight puffs was a valid approximation of the standard analytical smoking procedure, tar and nicotine deter-

Table 1. Tar and nicotine analyses.

\begin{tabular}{|c|c|c|c|c|}
\hline & \multicolumn{2}{|c|}{ 30-Port smoker } & \multicolumn{2}{|c|}{$\begin{array}{l}\text { Phipps \& Bird } \\
\text { smoker }\end{array}$} \\
\hline & Mean & $\begin{array}{l}\text { Standard } \\
\text { deviation }\end{array}$ & Mean & $\begin{array}{l}\text { Standard } \\
\text { deviation }\end{array}$ \\
\hline Cigarette weight (g) & 1.130 & .0057 & 1.130 & .0057 \\
\hline Pressure drop (mm $\mathrm{H}_{2} \mathrm{O}$ ) & 68.0 & 2.15 & 68.0 & 2.15 \\
\hline Water (mg/cig.) & 2.6 & .38 & 2.6 & 0.11 \\
\hline $\begin{array}{l}\text { Dry particulate material" } \\
\text { (mg/clg.) }\end{array}$ & 22.5 & 3.19 & 23.4 & 0.71 \\
\hline Nicotine (mg/cig.) & 1.83 & 30.102 & 1.71 & 0.07 \\
\hline $\begin{array}{l}\text { Corrected particulate } \\
\text { material"* (mg/cig.) }\end{array}$ & 21.2 & 3.83 & 21.4 & 1.25 \\
\hline Number of putfs & 8 & 8 & 8 & 3 \\
\hline
\end{tabular}

- D.P.M.: The material collected on a Cambridge fllter pad less water.

" C.P.M.: The material collected on a Cambridge fllter pad less water and nlcotine, and often referred to as "tar". 
Table 2.

4,4-Dichlorobenzo-

phenone (DBP) $(\mu \mathrm{g})$

1. Apparatus, undiluted smoke

862

2. Apparatus, diluted smoke

90

3. Total smoke

20050

Loss of DBP in apparatus : $4.3 \%$ (undiluted)

Loss of DBP in apparatus : . $45 \%$ (10\% smoke)

The loss of DBP represents the loss of particulate matter.

minations were performed on a group of carefully selected $I R_{1}$ cigarettes. A group of cigarettes was selected by weight (within \pm 10 $\mathrm{mg}$ of the mean weight) and by pressure drop (within $\pm 5 \mathrm{~mm}$ of the mean pressure drop) after having been conditioned for 24 hours at $75^{\circ} \mathrm{F}$ and $60 \%$ relative humidity. This group was then divided into two groups, one for smoking on the standard Phipps and Bird analytical smoker and one for smoking on the 30-port reverse smoking machine. Ninety cigarettes were smoked on the latter machine and the condensate collected on 20 previously weighed Cambridge filter pads positioned around a 20-port manifold. The other group (100 cigarettes) was smoked according to the standard Federal Trade Commission (FTC) procedure on the Phipps and Bird 20-port machine. The analyses for tar, nicotine, and water were carried out according to the FTC methods (Table I).

Deposition within the apparatus was assessed by smoking cigarettes containing $3880 \pm 466 \mu \mathrm{Hg} 44^{-}$ dichlorobenzophenone (DBP) and comparing the amount extracted from the apparatus to that retained on the filter pad. The analytical procedures involved have been reported previously (4). The data in Table 2 represents two determinations, one conducted with whole smoke alone and one in which the smoke was immediately diluted to $10 \%$ concentration with air. A dramatic decrease in deposition, as measured by this method, takes place when the smoke is diluted.

The determination of several fixed gases was carried out using $I R I$ cigarettes in the machine reported here and compared to the results produced by a single port syringe type smoking machine. Thirty $1 R_{1}$ cigarettes were smoked eight puffs each on the reverse puff machine using a dilution ratio of 9 parts air to one part smoke, giving a total volume of 84 liters. The total gases generated were collected in a Tedlar $^{\$}$ (polyvinyl fluoride) bag after passing through a $142 \mathrm{~mm}$ diameter Cambridge filter pad to remove the particulate matter. Samples of the contained gas were then introduced into the gas sampling loop of a gas chromatograph and analyzed for carbon monoxide, carbon dioxide, oxygen, nitrogen, and methane (5).

The results are presented in Table 3 along with the results obtained similarly from $I R I$ cigarettes smoked 8 puffs on a single port syringe type smoker similar in operation to the multiport Phipps and Bird analytical smoking machine.

In a separate experiment, gas was collected from the exhaust manifold of the Phipps and Bird analytical smoking machine and analyzed for carbon monoxide and carbon dioxide. Since the degree of dilution due to dead volume within the apparatus was unknown, the percentages or absolute yield per cigarette of these gases could not be calculated from the analysis; however, the ratio of $\mathrm{CO} / \mathrm{CO}_{2}$ was determined to be $0.492 \pm 0.003$. A similar determination made using gas phase generated by the 30-port reverse smoking machine described above gave a $\mathrm{CO} / \mathrm{CO}_{2}$ ratio of $0.475 \pm 0.002$.

Mikami et al. (6) have reported data indicating that the $\mathrm{CO} / \mathrm{CO}_{2}$ ratio is a rather sensitive indicator of puff volume. They determined this ratio to be 0.50 for the standard $35 \mathrm{~cm}^{3} / 2$-second puff regime.

The values for $4.1 \%$ by volume $\mathrm{CO}$ and $8.6 \% \mathrm{CO}_{2}$ determined from the gas sample from the reverse smoker agree well with those for IRI cigarettes reported by Guerin (7). His analysis gave $4.5 \% \mathrm{CO}$ and $8.4 \%$ $\mathrm{CO}_{2}$.

A number of polycyclic hydrocarbons were analyzed in smoke condensate generated by the 30-port reverse smoker for comparison with similar data obtained on tar from a vacuum type machine (Borgwaldt Model $\mathrm{M}$ 9). The condensates collected for these analyses were collected in cold traps at dry ice temperature and were subsequently dried by codistillation of the water with acetone at $40^{\circ} \mathrm{C}$ under vacuum. The data in Table 4 is expressed in terms of gas chromatographic peak area units. These units can be converted to weight units by application of the appropriate response factors, but this was not done since the purpose of the analysis was

Table 3. Fixed gases from $1 R 1$ clgarettes.

\begin{tabular}{|c|c|c|c|c|c|c|}
\hline \multirow{2}{*}{$\begin{array}{c}\text { Machine } \\
\text { type }\end{array}$} & \multirow{2}{*}{$\begin{array}{l}\text { No. of } \\
\text { puffs }\end{array}$} & \multicolumn{5}{|c|}{ Milligrams percigarette* } \\
\hline & & $\mathrm{CO}$ & $\mathrm{CO}_{2}$ & $\mathrm{O}_{2}$ & $\mathrm{~N}_{2}$ & $\mathrm{CH}_{4}$ \\
\hline $\begin{array}{l}\text { 30-Port } \\
\text { reverse } \\
\text { smoker }\end{array}$ & 8.0 & $13.91 \pm .34$ & $45.24 \pm 0.78$ & $44.19 \pm 0.8$ & $214.31 \pm 0.82$ & $1.08 \pm 0.03$ \\
\hline $\begin{array}{l}\text { Syringe } \\
\text { type } \\
\text { smoker }\end{array}$ & 8.0 & $16.50 \pm .40$ & $46.19 \pm 4.04$ & $44.93 \pm 1.17$ & $221.25 \pm 3.27$ & $1.03 \pm 0.10$ \\
\hline
\end{tabular}

- Replicate determination, \pm one standard devlation. Data not corrected for thermal conductivity response factors. 


\begin{tabular}{l|c|c}
\hline \multirow{2}{*}{ Compound } & \multicolumn{2}{|c}{$\begin{array}{c}\text { Units per gram condensate } \\
\text { corrected to 100\% recovery }\end{array}$} \\
\cline { 2 - 3 } & $\begin{array}{c}30 \text {-Port } \\
\text { reverse smoker }\end{array}$ & $\begin{array}{c}\text { Borgwaldt } \\
\text { smoker }\end{array}$ \\
\hline Benzanthracene & 198 & 186 \\
Chrysene & 297 & 307 \\
Benzofloranthrenes & 81.6 & 82.0 \\
Benzo(e)pyrene & 39.6 & 38.3 \\
Benzo(a)pyrene & 59.4 & 54.8 \\
Indole & $466 \cdot 10^{3}$ & $492 \cdot 10^{3}$ \\
3-Methylindole & $352 \cdot 10^{3}$ & $338 \cdot 10^{3}$ \\
3-Ethylindole & $95 \cdot 10^{3}$ & $93 \cdot 10^{3}$ \\
Carbazole & $35 \cdot 10^{3}$ & $25 \cdot 10^{3}$ \\
\hline
\end{tabular}

only to compare the composition of the condensates from the two types of smoking machines. In each case, radiocarbon labeled benzo(a)pyrene was added to allow the calculation of the percent recovery of benzo(a)pyrene in the analysis. All of the polycyclic aromatic compounds reported have been corrected by the factor determined for benzo(a)pyrene recovery. The indole type compounds have not been corrected for recovery and are reported directly as measured.

Gas chromatographic analysis of some of the condensable gas phase components of smoke from $I R I$ cigarettes smoked on the 30-port reverse smoker and on a single port syringe type smoker was carried out by the method reported by Spears et al. (8). The results in Table 5 indicate that the gas phase compositions with respect to those materials analyzed was not significantly different between the two types of smoking machines.

\section{CONCLUSIONS}

The above data show that, within the expected analytical error of the methods involved in the various measurements, the smoke produced by the two different types of smoking is not chemically different. Because of the ability of the smoking machine described here to generate a continuous stream of smoke at one or several preset dilution ratios and because of the various automatic functions incorporated, one machine of this type could be used to support an animal inhalation experiment using as many as 2000-5000 mice, depending upon the exposure regime chosen.

\section{SUMMARY}

Experience gained from a recent evaluation of smoking machines has been applied in the design of a sophisticated automatic smoking machine. Utilizing a reverse puff mechanism, a continuous or intermittent smoke stream is generated, diluted to selected concentration levels and channelled to multiple exposure apparatus. All functions are completely controlled by digital
Table 5. Comparison of gas phase from two types of smoking machines.

\begin{tabular}{l|c|c}
\hline \multicolumn{1}{c|}{ Compound } & $\begin{array}{c}\text { 30-Port } \\
\text { reverse smoker }\end{array}$ & $\begin{array}{c}\text { Single port } \\
\text { syringe smoker }\end{array}$ \\
\hline Isoprene & $3533^{*}$ & $3328^{*}$ \\
Acetaldehyde & 1814 & 1937 \\
Acetone & 2487 & 2258 \\
Acrolein & 443 & 567 \\
2-Methylfuran & 381 & 402 \\
Benzene & 710 & 740 \\
Ethanol & 504 & 561 \\
Toluene & 1124 & 1210 \\
\hline
\end{tabular}

- All data are given in arbitrary units representing areas under chromatographic peaks.

electronics as is the detection of faults in the system. Analysis of the smoke produced indicates that it is not chemically different from the smoke delivered by other types of apparatus.

\section{ZUSAMMENFASSUNG}

Die Erfahrungen aus einer kürzlich durchgeführten Bewertung von Rauchmaschinen wurden beim Entwurf einer hochentwickelten automatischen Rauchmaschine angewandt. Unter Benutzung des Druckverrauchens wird ein kontinuierlicher oder intermittierender Rauchstrom erzeugt, auf gewählte Konzentrationen verdünnt und verschiedenen Apparaturen zugeleitet. Alle Funktionen einschließlich der Aufdeckung von Störungen werden vollständig durch Digitalelektronik kontrolliert. Die Untersuchung des erzeugten Rauches zeigte, daß dieser sich chemisch von dem Rauch anderer Maschinentypen nicht unterscheidet.

\section{RESUME}

Les données d'une étude récente de différentes machines à fumer ont été appliquées dans la conception d'une nouvelle machine à fumer automatique très perfectionnée. En utilisant un mécanisme de bouffée inversée, un flux de fumée continu ou intermittent est généré, dilué à des concentrations préalablement établies, et dirigé vers un appareil à expositions multiples. Toutes les fonctions sont complètement contrôlées par touches électroniques, ainsi que la détection des erreurs dans le système. L'analyse de la fumée produite montre qu'elle n'est chimiquement pas différente de la fumée produite par d'autres machines.

\section{REFERENCES}

1. Walton, R. R.: Smoking machine; U.S. Patent Specification No. 3, 476, 119.

2. Morrissey, C. A.: Cigarette smoking machine; U.S. Patent Specification No. 3, 528, 435. 
3. Eastem Scientific Co., 267 Plain Street, Providence, Rhode Island, o2905, USA.

4. Lewis, C. I., J. C. McGeady, J. R. Wagner, F. J. Schultz, A. W. Spears: Dichlorbenzophenone as a nonradioactive tracer for cigarette smoke-gas chromatographic analysis of tracer; Amer. Rev. Resp. Dis. 106 (1972) 480.

5. Hawkins, J. C.: Routine analysis of $\mathrm{CO}_{2}, \mathrm{H}_{2} \mathrm{O}, \mathrm{O}_{2}$, $\mathrm{CH}_{4}$ and $\mathrm{CO}$ by gas chromatography; Application Note ANC-19-70, Hewlett Packard Co., Avondale, Pennsylvania, 19311, USA.

6. Mikami, Y., N. Naito, and Y. Kaburaki: Effects of some factors on carbon monoxide concentration in main stream smoke of a cigarette; Japan Monopoly Corp. Central Res. Sci. Papers x13 (x97x) 49.

7. Guerin, M. R.: Tobacco smoke analysis program, Progress report for the period September 1, x970, to July 1, 1971; ORNL-4735, UC-41-Health and Safety, Oak Ridge National Laboratory, October, 1971.
8. Spears, A. W., and W. E. Routh: A combined approach to the quantitative analysis of the volatile components of cigarette smoke; Presented at the 18th Tobacco Chemists' Research Conference, Raleigh, N. C., October 20-22, 1964 .

\section{Adknowledgment}

The authors wish to acknowledge the contributions of M. D. Sidbury and W.P. Kirschstein in the mechanical design and development of the smoking machine.

The authors' address:

Lorillard Research Center, 420 English Street, P. O. Box 21688, Greensboro, North Carolina, 27420, USA. 